\title{
NATURAL AGEING OF STABILIZED AND UNSTABILIZED LDPE FILMS: XRD AND SEM ANALYSIS
}

\author{
Mourad Hamouya ${ }^{1}$, Aicha Mahir ${ }^{2}$, Mohamed Chafik EL Idrissi ${ }^{3}$ \\ ${ }^{\text {I}}$ Physics Department, Physics of surfaces and interfaces, Ibn Tofail University, kenitra, Morocco \\ ${ }^{2}$ Physics Department, Physics of surfaces and interfaces, Ibn Tofail University, kenitra, Morocco \\ ${ }^{3}$ Physics Department, Physics of surfaces and interfaces, Ibn Tofail University, kenitra, Morocco
}

\begin{abstract}
This article focuses on the study of both stabilized and unstabilized low-density polyethylene films aged under natural weathering in the middle of Morocco (Sidi Kacem city). The study was undertaken on three samples for each LDPE films: a new sample taken as reference; another exposed to outdoor weathering for one year; and a sample exposed for two years.

The natural ageing effects were followed by analysis of the X-ray diffraction (XRD). This technique provides information on the main physical properties and evaluates the internal causes of natural ageing of our samples. The XRD patterns show, in addition to the usual peaks relative to the planes (110), (200) and (020), the emergence of the new region 37-48 including different peaks that clearly start the natural ageing. Thus, the XRD parameters indicate the increase of degree the crystallinity and crystallite size with time exposure for all LLDPE and LDPE samples. However, the results obtained by the X-ray diffraction have been confirmed by observing the morphology of the samples with scanning electron microscopy technology (SEM).
\end{abstract}

Keywords: LDPES, LDPEUS, crystallinity, Natural ageing, XRD, SEM

\section{INTRODUCTION}

Polyethylene is the most widespread polymer in the world. It belongs to the family of the polyolefin. The annual production is approximately at 80 million metric tons in 2008 [1]. Especially, low-density polyethylene is widely used in greenhouses as covering material due to its dielectric properties combined with long durability [2], excellent chemical resistance [3, 4, 5], good resistance to cracking , low permeability to water vapor [6], low cost and easy manufacture $[2,7]$.

The exposure of low density polyethylene film under natural weathering is giving rise to degradation effects. However, weathering is commonly defined as the undesirable change produced by outdoor exposure [8]. The ageing of lowdensity polyethylene results in a slow, often irreversible deterioration of the chemical properties stemming from its own instability or the effect of the environment [9]. Thus, external environment factors such as leaching by rainwater, the ultraviolet radiation (UV) and seasonal variations in temperature can cause chemical degradation of polyethylene and its weakening [10].

The study of the photo-oxidation of low density polyethylene has been focused on the exposure of both commercial greenhouses to weathering conditions (outdoor) in the middle of Morocco (Sidi Kacem city). Thus, the study was undertaken on three samples for each agricultural greenhouse: a new sample taken as reference; another sample exposed to weathering for one year; and a sample exposed for two years.
The photodegradation of low density polyethylene film through the natural ageing was followed by testing of the Xray diffraction (XRD). This technique provides information on the crystalline structure of the material and to determine the degree of crystallinity one of the most important properties. Using this technique other factors are also evaluated; especially, the degree of crystallinity, density, the lattice spacing (interplanar), the crystal size and parameters of the unit cells. However, the analysis by scanning electron microscopy (SEM) can reveal comparisons of the surface morphology of the samples.

\section{EXPERIMENTAL}

\subsection{Material}

The commercial samples kinds (one stabilized and the other unstabilized) are supplied by the company MICATEXE (Company Production of Agricultural Films Morocco). They have densities known between 0.92 and 0.98 g.cm ${ }^{-3}$, thickness between 180 - 200 microns, and weight between 165.5 and $176.5 \mathrm{~g} / \mathrm{m}^{2}$. The average temperature of the production order is $200{ }^{\circ} \mathrm{C}$. Two unaged samples were analyzed by X-ray diffraction (XRD) and scanning electron microscopy (SEM) served as reference.

\subsection{Natural Ageing Exposure}

The four kinds of samples (stabilized and unstabilized) were exposed to natural weathering. Two were exposed for thirteen months and the other two were exposed for twentythree months. The exposure of these samples of the lowdensity polyethylene under natural weathering was carried out at the roof of a building in Sidi Kacem city of Morocco. 


\subsection{X-ray Diffractometer}

The Panalytical X'Pert Pro Diffractometer is a versatile instrument with many different optics and sample stages (Spinner PW3064), and which can be used for phase identification, crystallite size and quantitative analysis for bulk and thin films materials. The X'Pert Pro installed in UATRS of the National Centre for Scientific and Technical Research (CNRST), and it is equipped by a Prefix system that allows, through pre-aligned optical and interchangeable, rapidly changes configurations, a Anton Paar TTK450 high temperature chamber allowing to work under controlled atmosphere (vacuum, argon, nitrogen, air) and to reach temperatures ranging between $-193^{\circ} \mathrm{C}$ and $450^{\circ} \mathrm{C}$ and ultra fast $\mathrm{X}^{\prime}$ Celerator detector with RTMS (Real Time Multiple Strip) technology.

The usual mounting is Bragg-Brentano reflection (theta/2theta) with high speed configuration. The sample is disposed on a support placed in an Anton Paar TTK540 chamber. The operating power is $40 \mathrm{kV}$ and $35 \mathrm{~mA}$ for the $\mathrm{Cu}$ tube. At this power, the $\mathrm{X}$-ray tube is producing the maximum flux of $\mathrm{X}$-rays. The $\mathrm{X}$-rays produced arise from the electron bombardment of a cu-target in an X-ray generator tube. The $\mathrm{X}$-rays emitted by copper anode contains $k \alpha_{1}, k \alpha_{2}$ and $k_{\beta}$ emissions lines, this latter is eliminated by nickel (Ni) filter. The incoming fixed divergence slit can be interchanged, and a longitudinal divergence mask is used to prevent X-ray illumination of the sample holder, which in this case was Perspex. The X-ray diffracted may be passing through a radial soller slit and is collected by $X^{\prime}$ Celerator detector associated with a monochromator. The low density polyethylene sample is introduced in a capillary diameter of $0.7 \mathrm{~mm}$ and rotated on itself so as to limit the effects of preferred orientation. The slots of fixed differences in $0.10 \mathrm{~mm}$ can reduce the beam divergence. The diffraction pattern is collected by $\mathrm{X}^{\prime}$ Celerator detector associated with a secondary monochromator.

\subsection{Degree of crystallinity $X_{C}$}

The degree of crystallinity is one of the most important properties to differentiate of materials. The X-ray diffraction can also calculate the degree of crystallinity $\left(X_{C, G}\right)$ of our polyethylene samples. The area under the crystalline and amorphous portions was determined in arbitrary units and the degree of crystallinity $X_{C},{ }_{G}$ was calculated using the relation $[7,8,9]$.

$$
X_{C, G}=\frac{I_{c}}{I_{c}+I_{a}} \times 100
$$

The above equation developed by Hermans and Weidinger [11] and corrected by Ruland [12] and Farrow [13], the equation below have become more commonly estimated and calibrated to the measure of degree the crystallinity $X_{C}, w$.
$I_{c}, I_{a}$ stand for the integral of the scattering intensity of the crystalline and amorphous peaks respectively and $K_{x}=$ 0.884 calibration constant [14].

\subsection{Interplanar Distance}

The identification of crystalline phases by X-ray diffraction is made possible through the periodicities of the atomic arrangement crystals that are unique from one phase to another. The distance between the lattice planes is named lattice spacing or Interplanar $\left(d_{h k l}\right)$ [15], and can be calculated according to the Bragg's law:

$$
d_{h k l}=\frac{\lambda}{2 \sin \left(\theta_{h k l}\right)}
$$

$d_{h k l}, \theta_{h k l}, n$ and $\lambda=1.5418 \AA$ stand for the interplanar distance, the half angle of deviation, the order of refraction and the wavelength, respectively. Also, the Miller indices $(h, k, l)$, the crystallite size $\left(L_{h k l}\right)$ [16], and the interchain distance $\left(D_{i n t}\right)$ $[8,17]$ and the distortion parameter (Lattice strain) $[9,17]$ $\left(P_{d}\right)$ were calculated as follows.

$$
\begin{aligned}
& \left(d_{h k l}\right)^{-2}=(h / a)^{2}+(k / b)^{2}+(l / c)^{2} \\
& L_{h k l}=\frac{K \lambda}{\beta \cdot \cos \left(\theta_{h k l}\right)} \\
& D_{\text {int }}=\frac{5 \cdot \lambda}{8 \cdot \sin (\theta)} \\
& P_{d}=\frac{\beta}{\tan (\theta)}
\end{aligned}
$$

Where $(a, b, c)$ are the parameters of an orthorhombic unit cell of polyethylene [16] and $\beta$ is the half-height width of the crystalline peak and $\lambda$ the wavelength of $\mathrm{X}$-ray radiation and $k$ the Scherrer constant taken as $0,9[9]$.

\subsection{Scanning Electron Microscopy}

The observation of the samples in cutting or in surface was realized on a device of method ESEM with a gas pressure in the room being able to go until $26 \mathrm{~m}$ bar. It is also the only allowing microscope to work in three methods of different emptiness: high vacuum (10-6 mbar), low vacuum (0.1-1.33 mbar), and environmental (1.33-26 mbar). And for each of these methods a detector of the secondary electrons that furnishes non-drivers without any preparation, it also allows to observe in a dynamic manner of the materials under a given environment (pressure, temperature, gas composition). It remains topographic on the sample. The method ESEM eliminates totally the effects of loads and allows the observation of samples non-drivers without any preparation. Equipped with a complete system of microanalyses $\mathrm{X}$ (Detector EDX-EDAX) and of a detector of the electrons retro diffused, it allows giving the chemical composition of this[18, 19].

$$
X_{c, w}=\frac{I_{c}}{I_{c}+k_{x} \cdot I_{a}} \times 100
$$




\section{RESULTS AND DISCUSSION}

\subsection{X-ray Diffraction}

The results from X-ray diffraction of two virgin low density polyethylene (LDPEUS and LDPES) samples are shown in Fig-1. These patterns illustrate the presence of the usual peaks relative to the planes (110), (200) and (020) with the increase in their intensity and an increase in the amorphous band of LDPEUS than LDPES.

The exposure of low density polyethylene film under natural weathering is giving rise to degradation effects. The x-ray diffraction of the LDPEUS aged under natural weathering for the one and two years is shown on Fig-2. These results reveal the increase in the intensity of the peaks relative to the planes (110) and (200) with the exposure time and decreases in the amorphous band. Thus, one of the two crystalline peaks in Fig-2 is located in the angular range $20.5-22.2^{\circ}$ and another in the range $23-24.7^{\circ}$. This finding confirms the crystallinity of polyethylene, which corresponds to an orthorhombic unit cell. These peaks are well characterized in LDPE and correspond to specific crystallographic planes (110) and (200) [9].

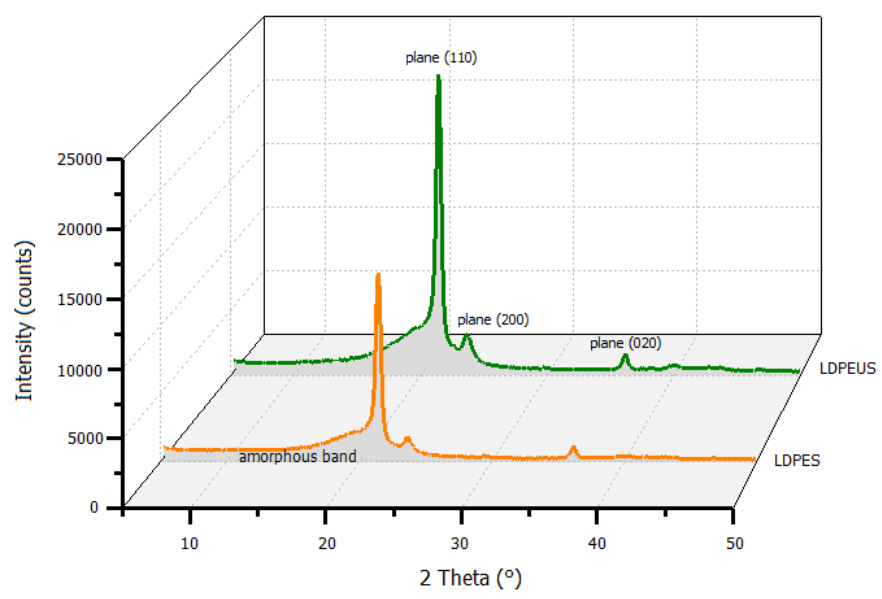

Fig-1: X-ray diffraction patterns of the virgin LDPEUS and LDPES

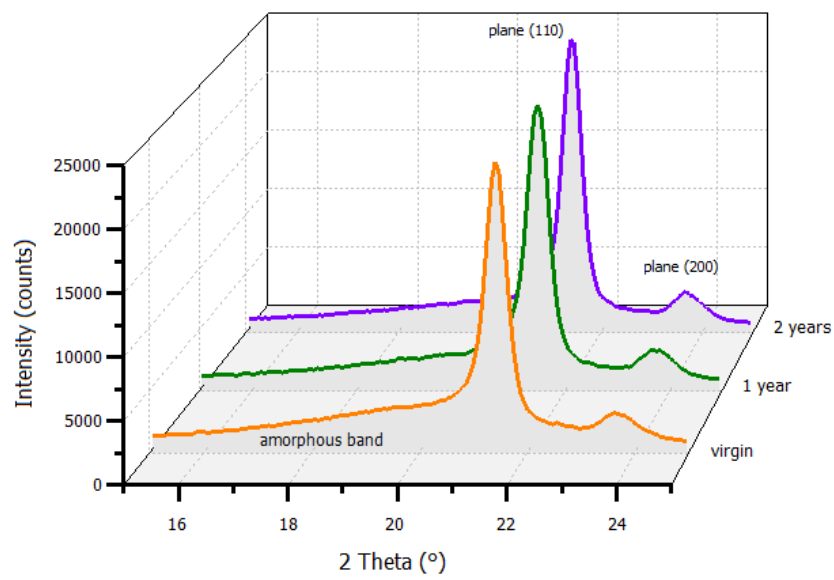

Fig-2: X-ray diffraction patterns of the LDPEUS samples, $2 \theta=15-25^{\circ}$
In Fig-3 we observe an increase in the intensity of the peak relative to the plane (020) and we notice, in addition to the peaks previously identified, the emergence of the new region $37-48^{\circ}$ including different peaks that clearly start the natural ageing. However, the strongest peak at $43.60^{\circ}$ that appears after two years correspond to the plane (220) and others peaks relative to the planes (120), (011) and (201).

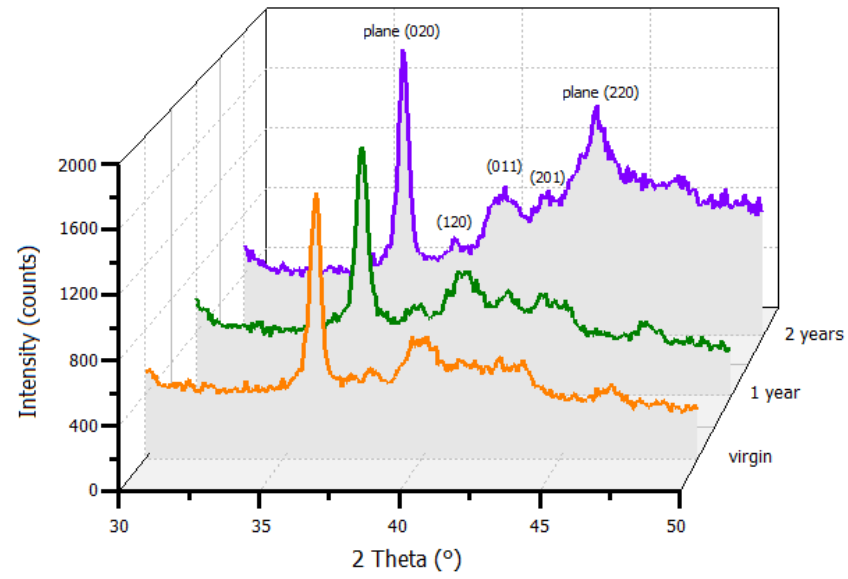

Fig-3: X-ray diffraction patterns of the LDPEUS samples, $2 \theta=30-50^{\circ}$

Therefore, the X-ray diffraction of the LDPES samples is shown in Fig-4. We have obtained the same remarks that are listed above in Fig-2. These results indicate the increase in intensity of the peaks corresponds to plans (110) and (200) and an increase in the amorphous band.

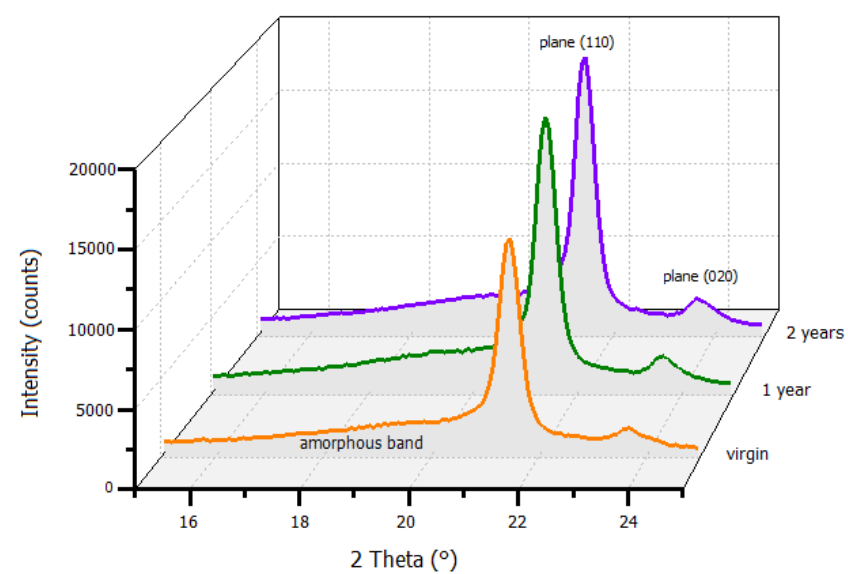

Fig-4: X-ray diffraction patterns of the LDPES samples, $2 \theta=15-25^{\circ}$

In Fig-5 we observe an increase in the intensity of the peak relative to the plane (020) and emergence the strongest peak at $43.53^{\circ}$ after one year correspond to the plane (220) of LDPES than to the LDPEUS sample ( after two years).

Tables-1 and $\mathbf{2}$ are shown the different X-ray diffraction parameters for all the LDPEUS and LDPES samples. For the LDPEUS can be seen that the two parameters $(a, c)$ and volume the orthorhombic unit cell decreases with exposure time and an increase of the parameter (b) after two years. In 
contrast, for LDPES we have an increase the volume and parameter (c) of orthorhombic unit cell.

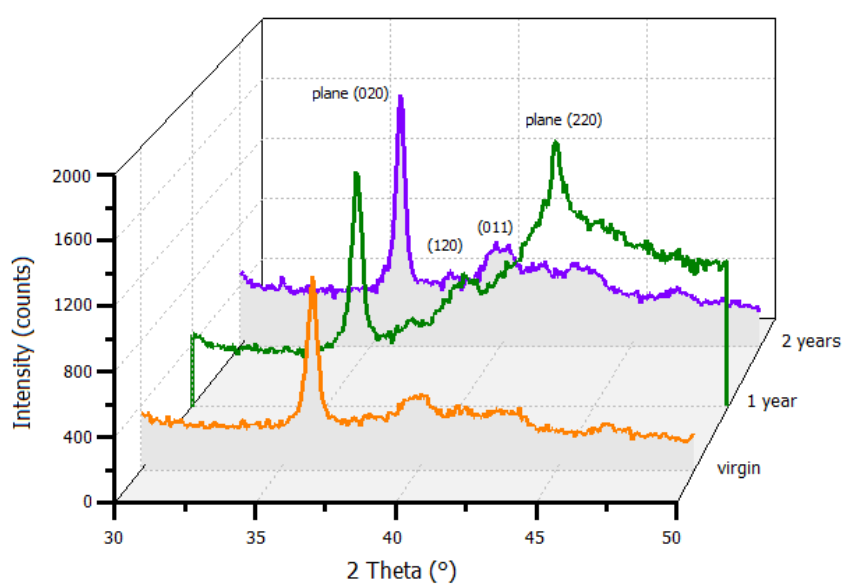

Fig-5: X-ray diffraction patterns of the LDPES samples, $2 \theta=30-50^{\circ}$

Table-1: XRD parameters for all LDPEUS samples

\begin{tabular}{|c|c|c|c|c|}
\hline $\begin{array}{c}\text { Exposure } \\
\text { time }\end{array}$ & $\begin{array}{c}\text { Peak } \\
\text { intensity }\end{array}$ & $\begin{array}{c}2 \text { Theta } \\
\left({ }^{\circ}\right)\end{array}$ & $\mathrm{d}(\mathrm{hkl})$ & $\begin{array}{c}\text { Plane } \\
(\mathrm{hkl})\end{array}$ \\
\hline New & 23176 & 21.41046 & 4.15006 & 110 \\
& 3170 & 23.61635 & 3.76718 & 200 \\
& 1652 & 36.18322 & 2.48247 & 020 \\
\hline & 34521 & 21.47731 & 4.13729 & 110 \\
One year & 1590 & 23.68320 & 3.75669 & 200 \\
& 801 & 40.06024 & 2.25071 & 011 \\
& 972 & 41,66452 & 2.16768 & 201 \\
\hline & 24790 & 21.41046 & 4.15006 & 110 \\
Two & 3576 & 23.68320 & 3.75669 & 200 \\
years & 1895 & 36.11638 & 2.48691 & 020 \\
& 994 & 38.12137 & 2.36060 & 120 \\
& 960 & 41,73137 & 2.16436 & 201 \\
& 1526 & 43.60303 & 2.07570 & 220 \\
\hline Exposure & $\mathrm{a}(\AA)$ & $\mathrm{b}(\AA)$ & $\mathrm{c}(\AA)$ & $\mathrm{V}(\AA) 3$ \\
time & & & & \\
\hline New & 7.53437 & 4.96495 & 2.52507 & 94.45724 \\
\hline One year & 7.51340 & 4.96495 & 2.52507 & 94.19435 \\
\hline Two & & & & \\
years & 7.51340 & 4.97383 & 2.52389 & 94.31872 \\
\hline
\end{tabular}

Table-2: XRD parameters for all LDPES samples

\begin{tabular}{|c|c|c|c|c|}
\hline $\begin{array}{c}\text { Exposure } \\
\text { time }\end{array}$ & $\begin{array}{c}\text { Peak } \\
\text { intensity }\end{array}$ & $\begin{array}{c}\text { 2Theta } \\
\left({ }^{\circ}\right)\end{array}$ & $\mathrm{d}(\mathrm{hkl})$ & $\begin{array}{c}\text { Plane } \\
(\mathrm{hkl})\end{array}$ \\
\hline \multirow{3}{*}{ New } & 13880 & 21.47731 & 4.13729 & 110 \\
& 1887 & 23.68320 & 3.75669 & 200 \\
& 1201 & 36.18322 & 2.48247 & 020 \\
\hline \multirow{5}{*}{ One year } & 18228 & 21.41046 & 4.15006 & 110 \\
& 2578 & 23.68320 & 3.75669 & 200 \\
& 1499 & 36.11638 & 2.48691 & 020 \\
& 563 & 38,25542 & 2.35263 & 120 \\
& 849 & 40,12708 & 2.24711 & 011 \\
& 1693 & 43.53618 & 2.07873 & 220 \\
\hline
\end{tabular}

\begin{tabular}{|c|c|c|c|c|}
\hline & 18931 & 21.47731 & 4.13729 & 110 \\
Two & 2644 & 23.68320 & 3.75669 & 200 \\
years & 1661 & 36.18322 & 2.48247 & 020 \\
& 497 & 38,05489 & 2.36457 & 120 \\
& 694 & 39,85970 & 2.26157 & 011 \\
\hline $\begin{array}{c}\text { Exposure } \\
\text { time }\end{array}$ & $\mathrm{a}(\AA)$ & $\mathrm{b}(\AA)$ & $\mathrm{c}(\AA)$ & $\mathrm{V}(\AA) 3$ \\
\hline New & 7.51338 & 4.96494 & 2.51998 & 94.0040 \\
\hline One year & 7.51338 & 4.97382 & 2.51882 & 94.12880 \\
\hline Two & & & & \\
years & 7.51338 & 4.96494 & 2.54042 & 94.76665 \\
\hline
\end{tabular}

$\mathrm{L}_{\mathrm{hkl}}, \mathrm{D}_{\mathrm{int}}$ and $\mathrm{P}_{\mathrm{d}}$ are calculated with respect to the most intense crystalline peak at the angular range $10.70-10.73^{\circ}$. The XRD data corresponding to the degree of crystallinity, the crystallite size, the interchain distance and the distortion parameter for LDPEUS and LDPES samples are listed in tables 3-4. This data displayed an increase the degree of crystallinity and crystallite size with time exposure. For LDPES we described the increase of $4.23 \%$ the degree of crystallinity after one year and $2.74 \%$ after two years for PEBDUS. This increase due to the replacement of $\mathrm{C}-\mathrm{H}$ bonds by $\mathrm{C}=\mathrm{O}$ in the amorphous band [20]. However, the secondary crystallization due to the change of seasonal temperature and can be improve the degree of crystallinity. The crystallite size increases, which is due to the further crystallization of small crystals. Interchain distances were remained the same because the angle of the peak did not vary significantly. Finally, the lattice strain decreases, which is due to the reorganization of the polymer network.

Table-3: Crystallinity for all LDPEUS and LDPES

\begin{tabular}{|c|c|c|c|}
\hline $\begin{array}{c}\text { Sample } \\
\text { type }\end{array}$ & $\begin{array}{c}\text { Exposure } \\
\text { time }\end{array}$ & $\mathrm{XC}, \mathrm{G}(\%)$ & $\mathrm{XC}, \mathrm{W}(\%)$ \\
\hline \multirow{3}{*}{ LDPEUS } & New & 64.16 & 66.94 \\
\cline { 2 - 4 } & One year & 62.20 & 65.06 \\
\cline { 2 - 4 } & Two years & 66.20 & 69.68 \\
\hline \multirow{3}{*}{ LDPES } & New & 63.73 & 66.55 \\
\cline { 2 - 4 } & One year & 68.23 & 70.84 \\
\cline { 2 - 4 } & Two years & 65.01 & 67.76 \\
\hline
\end{tabular}

Table-4: Crystallite size, Interchain distance and Distortion parameter for all LDPEUS and LDPES

\begin{tabular}{|c|c|c|c|c|}
\hline $\begin{array}{c}\text { Sample } \\
\text { type }\end{array}$ & $\beta$ & $\mathrm{L}_{\text {hkl }}(\AA)$ & $\mathrm{D}_{\text {int }}(\AA)$ & $\mathrm{P}_{\mathrm{d}}$ \\
\hline \multirow{4}{*}{ LDPEUS } & 0.62876 & 2.24600 & 5.18757 & 3.32595 \\
\cline { 2 - 5 } & 0.62967 & 2.24300 & 5.17161 & 3.32015 \\
\cline { 2 - 5 } & 0.54730 & 2.58029 & 5.18757 & 2.89505 \\
\hline \multirow{4}{*}{ LDPES } & 0,60193 & 2.34637 & 5.17161 & 3.17388 \\
\cline { 2 - 5 } & 0,58114 & 2.43004 & 5.18757 & 3.07405 \\
\cline { 2 - 5 } & 0,58894 & 2.39812 & 5.17161 & 3.10539 \\
\hline
\end{tabular}

\subsection{Scanning Electron Microscopy}

The micrographs of scanning electron microscopy (SEM) of two low-density polyethylenes are shown in Figs- 6-11. These show a difference between the morphology of the 
samples during the natural weathering exposure. We observe the presence of some white spots due to the existence of some vacuum from the liberation of gas during the treatment. Yet, the micrographs can show that the surface of the aged unstabilized LDPE samples is attacked more than the stabilized LDPE samples. This is explained by the increase in the amount of absorbed ultraviolet radiation and increased oxygen diffusion in the samples. Thus, the change in temperature, humidity and rainfall are climatic parameters capable of altering the surface morphology of the samples. These morphologies are a consequence of the increase in photo-oxidation reactions that brings breaking of chemical bonds of the macromolecular backbone of polymer.

Moreover, the existence of dust and air pollutants can affect the mechanism of degradation of the polymer surface. These results show that the unstabilized LDPE films undergo a remarkable degradation of climatic factors $\left(\mathrm{UV}, \mathrm{O}_{2}\right.$, humidity ...), which confirms the results obtained by infrared spectroscopy.

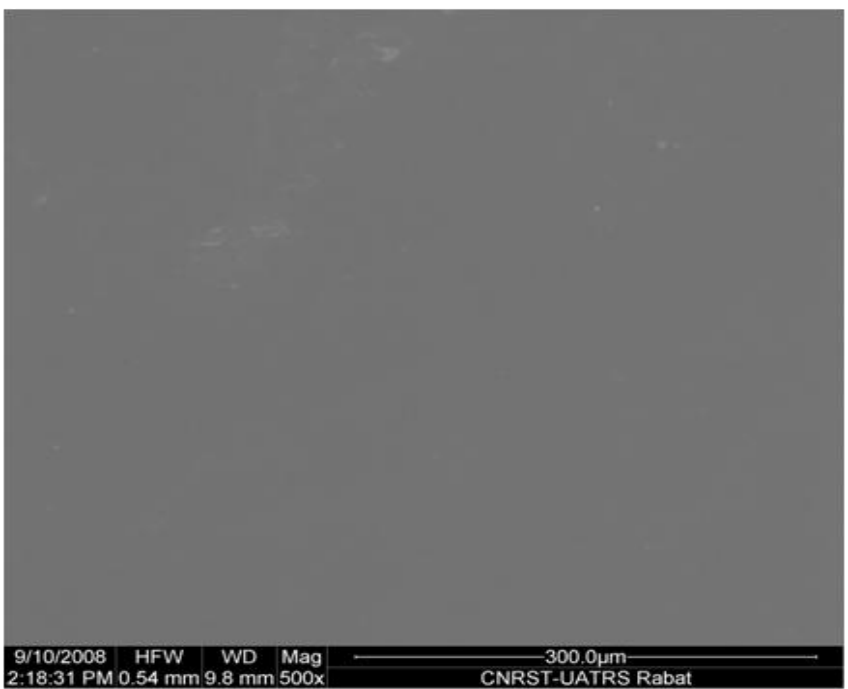

Fig-6: SEM micrograph of virgin LDPEUS sample

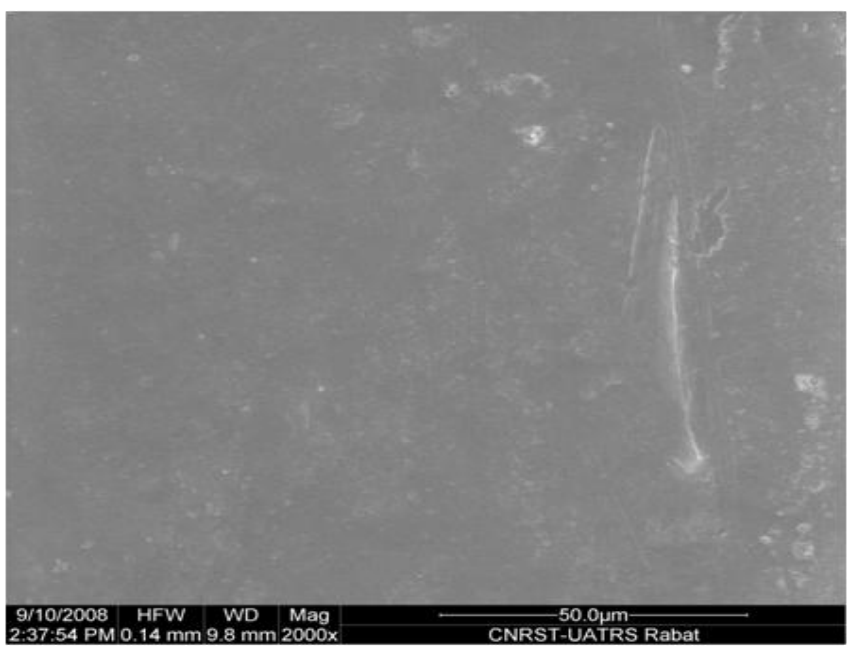

Fig-7: SEM micrograph of LDPEUS sample after one year

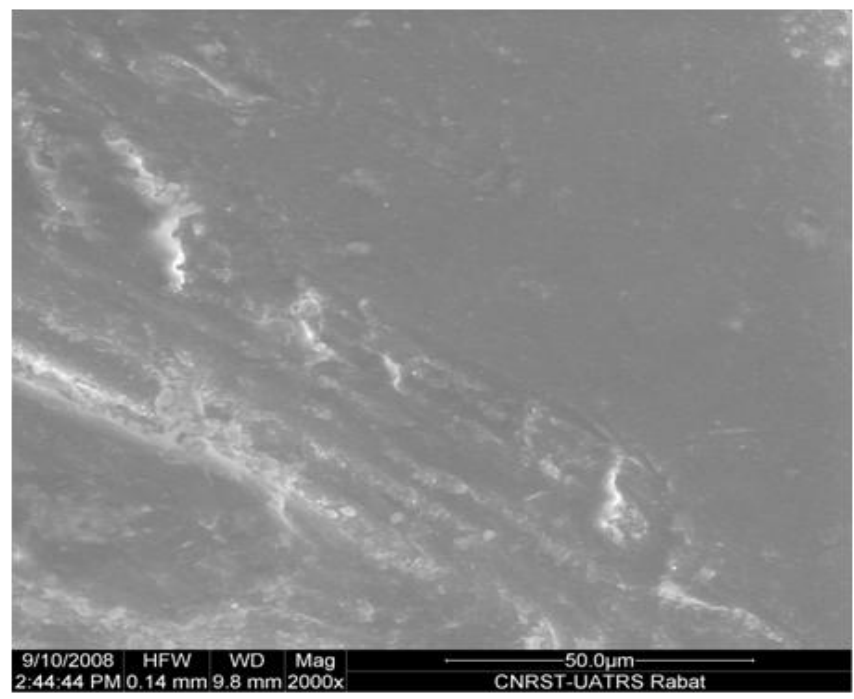

Fig-8: SEM micrograph of LDPEUS sample after two years

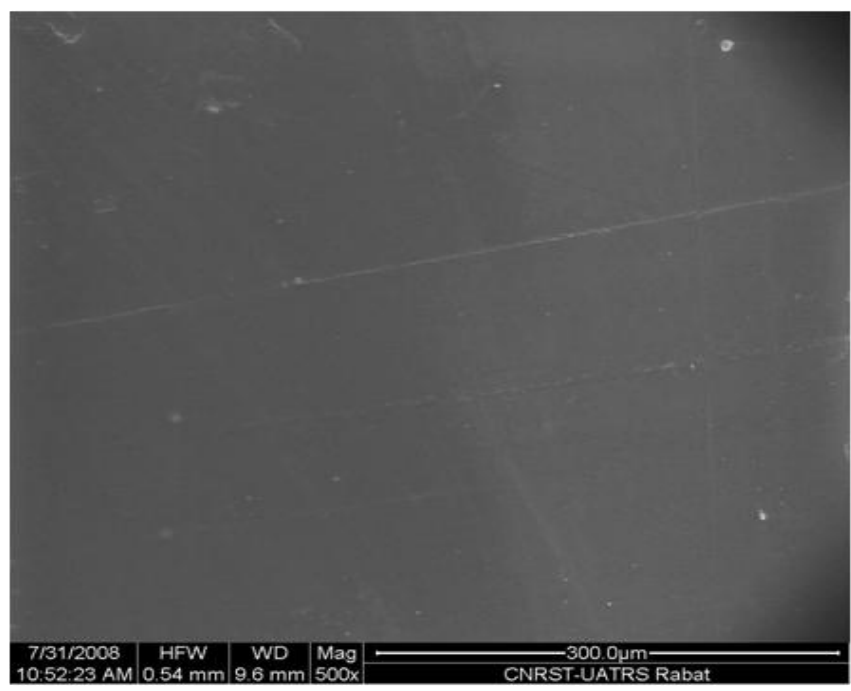

Fig-9: SEM micrograph of virgin LDPES sample

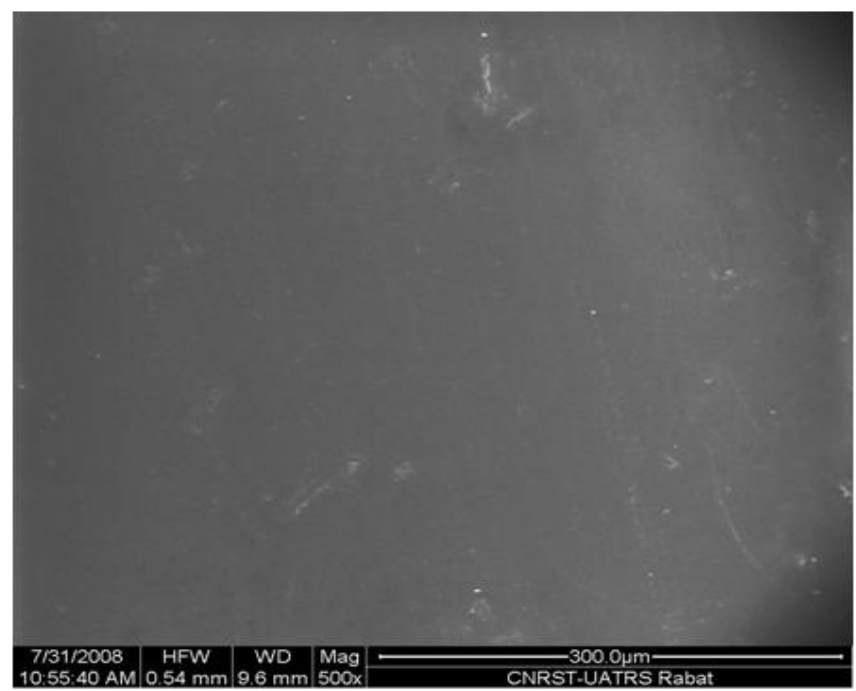

Fig-10: SEM micrograph of LDPES sample after one year 


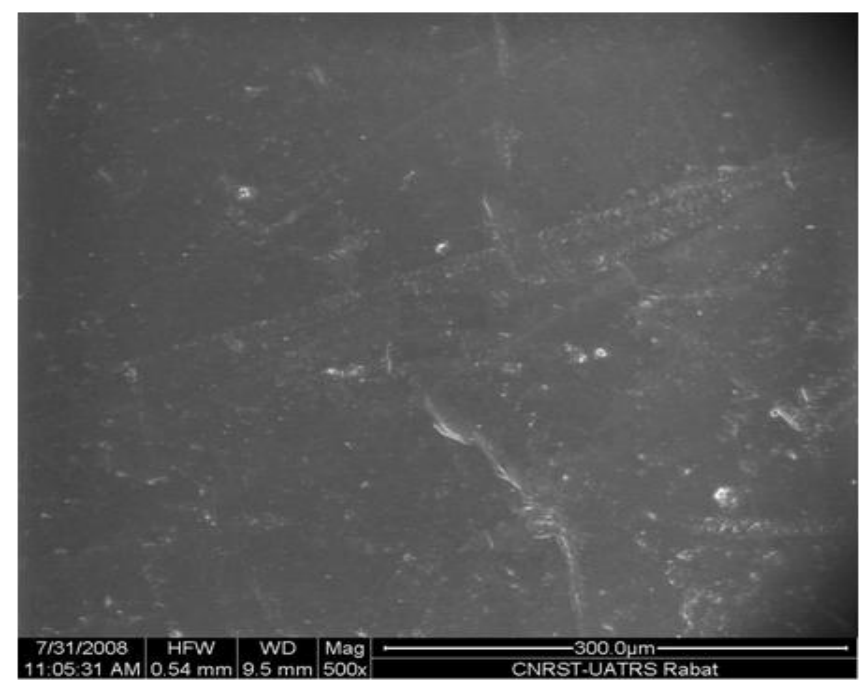

Fig-11: SEM micrograph of LDPES sample after two years

\section{CONCLUSION}

The X-ray diffraction (XRD) and scanning electron microscopy (SEM) were used to study the natural ageing of low-density polyethylene greenhouses covering films.

The study by XRD shows the presence of the peaks relative to the planes (110), (200) and (020) and the emergence of the new peak at the angular range of 43.50- $43.60^{\circ}$ correspond to the plane (220) with different time. The preferential oxidation of the amorphous phase relative to the crystalline phase is a result of the higher diffusion of oxygen within it. The peaks around this latter phase are due to oxidation processes. The results obtained by the infrared have been confirmed by observing the morphology of the samples with scanning electron microscopy technology.

\section{ACKNOWLEDGEMENTS}

Authors would like to acknowledge Prof. C. EL. Mohamed for the important contribution in infrared measurement of the polyethylene.

\section{REFERENCES}

[1] Trotignon. JP, Piperaud. M, Verdu. J, Dobraczynski. A, Summary of plastics, $5^{\text {TH }}$ ed, AFNOR 1991, p: 27-42.

[2] ISO-1872-1. Plastic - Polyéthylène (PE) moulding and extrusion materials. 1993 Part1: Désignation system and basis for spécifications.

[3] Nalwa HS. Handbook of low and high dielectric constant Materials and their applications-materials and processing, v.1. Academic, SanDiego. 1999

[4] Bartnikas R, Eichhorn RM. Engineering dielectrics. v.II A. ASTM Publications. Philadelphia. 1983

[5] Munaro M, L. Akcelrud L. Correlations between composition and crystallinity of LDPE/HDPE blends, J.Polym Res 2008 15:83-88.

[6] Füzessery S. Polyéthylène basse densité. No. A 3310. 1996. P. 7.
[7] Verdu. J, physical aging of plastics, 1990; A 3150 117.

[8] Guadagno. L, Naddeo. C, Vittoria V,Camino. G. Chemical and morphological modifications of irradiated linear and low density polyethylene films (LLDPE). J. Polym Degrad Stab, 2001; vol. 72, pp. 175-186. ISSN 0141-3910.

[9] Chattopadhyay. S, Chaki. TK, Bhowmick. AK. 2001. J. Appl, Polym. Sci 81 (8): 1936-1950.

[10] Madani. M, Structure, optical and thermal decomposition characters of LDPE graft copolymers synthesized by gamma irradiation. 2010; Bull. Mater. Sci., Vol. 33 (1): 65-73.

[11] Weidinger. A, Herman. PH, Makromolekulare Chemie.1961; pp: 50, 98.

[12] Ruland. W, X-ray determination of crystallinity and diffuse disorder scattering. Acta Crystallographica. 1961; pp: 14, 1180.

[13] Farrow. G, The measurement of crystallinity in polypropylene fibers by X-ray diffraction Polymer. 1961; pp: 2, 409.

[14] Fischer. E. W, Lorenz. R, Kolloid ZZ. Polym. 1963, PP.V.189 (2); PP : 97-110.

[15] Eberhart. JP, Structural Analysis and Chemical Materials. Dunod Bordas, 1989.

[16] Bunn. CW, The crystal structure of long-chain normal paraffin hydrocarbons. The "shape" of the $\mathrm{CH}_{2}$ group. Transactions of the Faraday Society. 1939, 35, PP: 482- 491.

[17] Alexander. LE, X-ray diffraction methods in polymer science, 1980; New York: Wiley Interscience.

[18] Rjeb M, Labzour A, Rjeb A, Sayouri S, ElIdrissi M.C, Massey S, Adnot A, Roy D. Condens Matter 2004; 5(2):168-172.

[19] Peterson JD, Vyazovkin S, Wight CA, Condens Matter 2001; 6:202.

[20] Billingham. NC, Prentice. P, Walker. TJ. Some effects of morphology on oxidation and stabilization of polyolefins J. Polym. Sci. Symp. 1976; 57, pp: 287-297. 